\title{
Obtaining the thin Semiconductive Covering Re-Se From Sulphate Electrolyte
}

\author{
E. A. Salakhova, A. M. Aliyev \\ Institute of Chemical Problems of the ANAS 29, H. Javid ave., AZ1143, Baku, Azerbaijan \\ Email: elza_salahova@mail.ru
}

Received 2012

\begin{abstract}
There have been investigated the kinetics and mechanism of the cathode electrodeposition of thin coverings Re-Se from the sulphate electrolyte, containing $\mathrm{NH}_{4} \mathrm{ReO}_{4}, \mathrm{SeO}_{2}$ and $\mathrm{H}_{2} \mathrm{SO}_{4}$. On the base of X-ray phase analysis and by the method of cyclic avometry there have been determined the content of obtained coverings, electrosettled at the various concentrations of components in electrolyte. the co-deposition process was shown to be attended by depolarization, which is due to the energy release upon the formation of the alloy.
\end{abstract}

Keywords: Electrodeposition; Alloys; Rhenium; Selen; Semiconductive Cover

\section{Introduction}

Rhenium and its alloys have a unique physico-chemical property, which provides their application in the most important fields of modern technology [1,2]. The high temperature of melting and stable mechanical properties at the high temperatures provided its application in the heat-resistant alloys production. The alloys of rhenium with selenium in the form of thin photosensitive films are used in semi-conducting technology. The semi-conducting films of alloys of rhenium with selenium are usually obtained by the method of separate components meeting together $[3,4]$. As the mentioned above method is rather difficult, it demands complicated instruments and the process is going at the high temperatures, we tried to apply electrochemical method based on the electrolysis of water solutions of selenium dioxide and ammonium perrenate in sulphuric acid for obtaining the thin coverings of Re-Se alloys.

In order to obtain Re-Se alloy from the sulphate electrolyte $[5,6]$ we studied the joint electrodeposition of rhenium with selenium and there was found the optimal regime for obtaining a semi-conducting alloy.

Analysis of results of indicated works showed that films depend not only on the composition and nature of electrolyte, but also on the material of cathode.

The use of different according to the origin electrolytes in order to obtain the thin coverings Re-Se, is certainly connected with the hardships which are usually met in every concrete occasion and it's directed to the search of the electrolyte composition, which gives the chance of obtaining the qualified cathode films, suitable for use in different fields of modern technology.

The present work is a continuation of our investigations in the field of electrochemical obtaining the semi-conducting alloys Re-Se and it's devoted to the study of scientific basis of the joint electrodeposition Re-Se alloy by the method of cycling avometry.

\section{Methods of Experiment}

For making the experiment there have been used the following reactants: $\mathrm{SeO}_{2}, \mathrm{H}_{2} \mathrm{SO}_{4}$ (chemical pure) and $\mathrm{NH}_{4} \mathrm{ReO}_{4}$ (pure for analysis). The experiments have been made in a glass cell provided with the water jacket.

The cycling avometer curves' have been reading taken by means of potentiostat $\mathrm{P}-5827 \mathrm{M}$ and $2 \mathrm{D}$ registering device PDP4-002. As a working electrode there have been used a platinum electrode with 0.15 square $\mathrm{cm}$, and as comparative electrode there have been used a chlorine-silver plate electrode, as anode - the platinum plate with 4 square sm. The acidity of solution was determined by $\mathrm{pH}$-meter $673 \mathrm{M}$ with the glass electrode. The temperature of electrolyte was regulated by means of thermostat UH. the content of Re-Se alloy components has been analyzed as the following: $10 \mathrm{ml}$ of concentrated $\mathrm{HNO}_{3}$ were dissolved while heating and after repeated evaporation in the water boiler-both there was added $5 \mathrm{n}$ of $\mathrm{H}_{3} \mathrm{PO}_{4}$ to the solution. The obtained solution has been diluted in the measured retort till $50 \mathrm{ml}$ and then by extraction with isoamyl spirit rhenium was separated from selenium. The rhenium has been determined by photometry of rodanide complex at the device FEK-56M [7], and selenium has been determined by thiocarbomide complex [8].

$\mathrm{X}$-ray graphical investigations of thin films Re-Se have been carried out at difractometer URS-55 in $\mathrm{CuK}_{\alpha}$-irradiation in RKD camera 57,3.

\section{The Results and Their Discussion}

In order to study the mechanism of formation Re-Se alloy there have been measured cycling avometer curves in different according to composition electrolytes as well as there was held the chemical and X-ray difractive analysis of cathode settlements, obtained at the certain potentials.

For detailed investigation of the process of obtaining the thin electrolytic coverings of Re-Se alloys you must have the information about kinetics of deposition of separate components and 
alloys. With this aim there were indicated the polar curves of Re-Se alloys extractions and of the separate metals at the platinum electrode.

As it is known the rhenium stays in sulphate electrolytes in the form of $\mathrm{ReO}_{4}{ }^{-}$and its reduction consists of several separate processes.

$$
\mathrm{ReO}_{4}{ }^{-}+8 \mathrm{H}^{+}+7 \mathrm{e} \rightarrow \mathrm{Re}+4 \mathrm{H}_{2} \mathrm{O}
$$

According to the work [9] the degree of $\mathrm{ReO}_{4}^{-}$-ions goes stage-by-stage and each stage of formation the intermediate products is characterized by a certain electrode potential, which becomes more negative in the process of rehabilitation, which can also provide the approach of Re and Se potentials settlement.

$$
\begin{gathered}
\mathrm{ReO}_{4}^{-}+2 \mathrm{H}^{+}+\mathrm{e} \rightarrow \mathrm{ReO}_{3}+\mathrm{H}_{2} \mathrm{O} ; \mathrm{E}_{1}=+0,77 \mathrm{~V} \\
\mathrm{ReO}_{3}+2 \mathrm{H}^{+}+2 \mathrm{e} \rightarrow \mathrm{ReO}_{2}+\mathrm{H}_{2} \mathrm{O} ; \mathrm{E}_{2}=+0,4 \mathrm{~V} \\
\mathrm{ReO}_{2}+4 \mathrm{H}^{+}+4 \mathrm{e} \rightarrow \mathrm{Re}+2 \mathrm{H}_{2} \mathrm{O} ; \mathrm{E}_{3}=+0,26 \mathrm{~V}
\end{gathered}
$$

Thus, the rhenium reduction in strong acid electrolytes goes according to the stage, through the formation of intermediate oxides film, about which tell us red and blue sediments in the obtained film.

In order to have a whole information about the joint electrodeposition of Re with Se, there were measured the cycling polar curves of rhenium in sulfate electrolyte at the different involutions. There are two sharp waves on the curve of a cathode halfcycle. One of them is at the potential $0,2-0,3 \mathrm{~V}$, the other at $(-0,3)-(0,4) \mathrm{V}$ (s.c.e). Formation of these waves can be explained by the step mechanism of reduction the perrenate ions. The character of anode halfcycle also proves this suggestion. The anode wave forming at the potential $0,1-0,2 \mathrm{~V}$ (s.c.e.) can be explained by Re dissolving, and distinctly expressed peaks to dissolving of $\mathrm{ReO}_{3}$ and $\mathrm{ReO}_{2}$ correspondingly.

There have been studied the dependence of involution rate of potential on the rise of limited current value. Dependence of limited current from square root of potential involution rate has a rectilinear character, which is observed in those cases, when the deposition rate is controlled by ions diffusion to the surface of cathode.

Then, in order to have additional information about the processes taking place while Se deposition, there were measured cycling polar curves of Se in sulphate solutions at the different involution.

As it can be seen in the diagram on the cycling volt-ampere curves of cathode deposition and anode oxidation of Se there appears a wave, which refers correspondingly to rehabilitation of $\mathrm{SeO}_{3}{ }^{2-}$ till Se and to oxidation of the obtained product till $\mathrm{SeO}_{3}{ }^{2-}$. As well as it can be seen from the diagram that with the rise of evolution rate the volt-ampere curves are shifted to the positive side and at the involution of $80 \mathrm{mV} / \mathrm{sec}$ the wave disappears and there is formed a maximum limited current.

Perhaps, while formation the wave of reduction the main role plays the high resistance of created semi-conducting layer of Se, and therefore the process velocity decreases. With shifting the potential to the negative side a stormy discharge of hydrogen on the cathode takes place.

It's been established, that electrochemical formation of thin layer films goes through a number of complicated electrochemical reactions.
One of the factors influencing simultaneous deposition of electrolyte components is the state of a platinum cathode. It's also well-known, that electrocatalytic activity of electrode surface can change while depositing the other metals in a small quantity.

There were suggested several various mechanisms of electrochemical rehabilitation of Se [10], in the field of positive potentials (from +0.75 to $+0.35 \mathrm{~V}$ s.c.e.).

As it follows from these works, deposition of $\mathrm{H}_{2} \mathrm{SO}_{3}$ is a multistage process. At the first stage the adsorption of se acid takes place, where on the surface of electrode the adsorbed compounds of Se with intermediate degree of oxidation are being formed.

There have been shown the typical avogrammes of $\mathrm{SeO}_{2}$ solution in sulphuric acid at the platinum electrode. According to the results of investigations [5], the processes concerning peaks $\mathrm{C}_{1}$ and $\mathrm{C}_{2}$ are connected with formation of adsorbed compounds of Se with intermediate degrees of oxidation on the electron surface:

1) deposition and reduction of Se compounds (IV) on the active surface of platinum electrode

$$
\mathrm{H}_{2} \mathrm{SeO}_{3}+2 \mathrm{H}^{+}+2 \mathrm{e} \rightarrow \mathrm{H}_{2} \mathrm{SeO}_{2}(\mathrm{Pt})+\mathrm{H}_{2} \mathrm{O} ; \mathrm{E}=+0.70 \mathrm{~V}
$$

2) the current of reduction $\mathrm{C}_{2}$ is connected with the process an substrate surface, which reminds the deposition of amorphous Se:

$$
\mathrm{H}_{2} \mathrm{SeO}_{2}(\mathrm{Pt})+2 \mathrm{H}^{+}+2 \mathrm{e} \rightarrow \mathrm{OSe}(\mathrm{Pt})+2 \mathrm{H}_{2} \mathrm{O} ; \mathrm{E}=+0.35 \mathrm{~V}
$$

Our results are coordinated with the literature information.

In order to investigate the joint electrodeposition and to study kinetics and mechanism of the process of joint electrodeposition of Re with We from sulphate electrolyte there were taken the cycling voltamper curves of Se, Re and Re-Se alloy. The Re deposition on platinum electrode takes place at the potential about $0.6 \mathrm{~V}$ (s.c.e), and $\mathrm{Se}-$ at $0.5 \mathrm{~V}$ (s.c.e.). the curves of alloy are quite different from the curves taken from solutions, having separate components. The joint deposition of Re with We takes place at the more positive potentials, than these metals extraction separately, i.e. both components in alloy are extracted by depolarization. Such location of polar curves is observed in those cases, when it's possible to form a chemical compound on the cathode. The depolarization itself is a direct evidence of the fact that at the joint deposition there is a chemical interaction between the components with formation of $\mathrm{ReSe}_{2}$ on the cathode.

$$
\mathrm{Re}+2 \mathrm{Se} \rightarrow \mathrm{ReSe}_{2}
$$

At the change of the direction of potential evolution on the anode semi-cycles of voltampere curves, being obtained for individual components, there is observed just one peak of anode oxidation. For rhenium the pear of oxidation starts at the potential $0.6 \mathrm{~V}$ (s.c.e.) and for Se about $0.95 \mathrm{~V}$ (s.c.e.).

However, there have been observed 3 peaks of anode oxidation on the voltampere curve of the anode semi-cycle. The peaks of oxidation, observed at 0.60 and $0.95 \mathrm{~V}$ (s.c.e.) no doubt, are caused by Re and Se oxidation. The new peak of oxidation, observed at the potential $0.80 \mathrm{~V}$ (s.c.e.) refers to the oxidation of complex $\mathrm{ReSe}_{2}$, forming on the cathode according to the reaction

$$
\operatorname{ReSe} 2=\operatorname{Re}+2 \mathrm{Se}+2 \mathrm{e}
$$


Hence, at the indicated potentials on the cathode the joint deposition of Re with Se doesn't take place and the only cathodic product is Se.

The joint deposition of Re with Se starts at the potential some about $0.20 \mathrm{~V}$ (s.c.e.) which is confirmed by the appearance on the curve the anodic semi-cycle of the second wave of anodic current at the potential $0.80 \mathrm{~V}$ (s.c.e.) connected with $\mathrm{ReSe}_{2}$ oxidation.

The sediment very close to $\mathrm{ReSe}_{2}$ according to the composition is obtained in the interval of potentials $0.15 \mathrm{~V}$ (s.c.e.). By shifting the potential to the negative side the content of Se in cathodic sediments is rising. These sediments consist of $\mathrm{ReSe}_{2}+\mathrm{Se}$. according to X-ray phaseous analysis, the films, having surplus quantity of Se and obtained at the potentials more positive than $0.25 \mathrm{~V}$, consist of two phases $\mathrm{ReSe}_{2}$ and Re.

The information taken from microanalyser showed that Re is mostly in the lower layers of the films. And the films rich with Se, obtained at the potential $0.10 \mathrm{~V}$, consist of two phases $\mathrm{ReSe}_{2}$ and Se. Here Se is located in the upper layers of the films.

The films, very close to $\mathrm{ReSe}_{2}$ according to their composition are formed in the interval of potentials $0.25 \mathrm{~V}$.

There were analyzed the content and morphology of thin layers $\mathrm{ReSe}_{2}$, electrodeposited on the platinum electrode. From the X-ray phaseous analysis it follows the film consist from $54 \%$ of Re and $46 \%$ of Se (according to the mass).

We have established that the compound $\mathrm{ReSe}_{2}$ is crystallized in triclinic syngony with the parameters of the lattice: $a=6.7275$ $\AA ; \mathrm{b}=6.6065 \AA$; $c=6.7196 \AA$.

\section{Conclusion}

There have been investigated the kinetics and mechanism of the cathode electrodeposition of thin coverings Re-Se from the sulphate electrolyte.

Was shown, that co-deposition of rhenium and selenium occur with some depolarization, which is due to the energy release upon the formation of the alloy.

\section{REFERENCES}

[1] Speranskaya E.F. Electrochemistry of Rhenium. p.53. Gylym, Alma-Ata, (1990)

[2] Obolonchik V.A., Yanaki A.A. Col. "Rhenium in the new Technics”. p. 59. Publishing House "Nauka”, Moscow, (1970)

[3] Obolonchik V.A., Mikhlina T.M. The Ukraine chemical journal, "Rhenium Selenide obtaining and properties" p. 1037-1040, v.30, Kyev, (1964)

[4] Opalovsky A.A., Fedorov V.Y., Lobkov Y.U. Journal Non-organic materials, "The new selenides and rhenium tellurides”. p. 144-148, Publishing House of the USSR AS, v. 1, No 2, (1971)

[5] Salakhova E.A. Az. Chem. Journal, "The joint reduction of rhenium and selenium in sulphuric acid solutions”, p.9-12, No 3, Baku, (1999)

[6] Salakhova E.A. Az. Chem. Journal, "The main regularities of the joint electrodeposition of Re with Se from sulphate electrolyte", No 4, Baku, (2003), p.140-144.

[7] Borisova L.V., Yermakov A.N. "Analytic chemistry of rhenium”. Publishing House "Nauka”, Moscow, (1974), p. 95.

[8] Nazarenko I.I., Yermakov A.N. "Analytic chemistry of Se and Te”. Publishing House "Nauka”, Moscow, (1971), p.46

[9] Salakhova E.A., Medjidzade V.A. at all "The electrodeposition of rhenium in alkalin and acidic electrolytes", Journal of Chemistry and Chemical Engineering, Volum 6, No 5, (2012), p.489-494.

[10] Dikstiene N. Electrochemistry, "Deposition of thin films Cu-Cd-Se”, v. 39, No 12, Moscow, (2003), p. 1487-1493 